\title{
Rewarding Family Medicine While Penalizing Comprehensiveness? Primary Care Payment Incentives and Health Reform: the Patient Protection and Affordable Care Act (PPACA)
}

\author{
Stephen Petterson, PhD, Andrew W. Bazemore, MD, MPH, \\ Robert L. Phillips, MD, MSPH, Imam M. Xierali, PhD, Jason Rinaldo, PhD, \\ Larry A. Green, MD, and James C. Puffer, MD
}

Family physicians' scope of work is exceptionally broad, particularly with increasing rurality. Provisions for Medicare bonus payment specified in the health care reform bill (the Patient Protection and Affordable Care Act) used a narrow definition of primary care that inadvertently offers family physicians disincentives to delivering comprehensive primary care. (J Am Board Fam Med 2011;24:637-638.)

Recognizing the value of the primary care function, the Patient Protection Affordable Care Act provided a $10 \%$ Medicare bonus to primary care practitioners. "Primary care practitioners" originally included family physicians, general internists, geriatricians, pediatricians, nurse practitioners, clinical nurse specialists, and physician assistants for whom primary care services represent $50 \%$ or more of their Medicare physician fee schedule-allowed charges in a prior period.

We used 2006 Part B Medicare claims data to estimate the percentage of any family physician's total charges for evaluation and management $(\mathrm{E} \& \mathrm{M})$ and three other key services reflective of differing scope across the rural to urban continuum (Figure 1). We then estimated the percentage of physicians eligible for the bonus in urban, large rural, small rural, isolated rural, and frontier areas.

Submitted 10 May 2011; revised 11 August 2011; accepted 15 August 2011.

From The Robert Graham Center

Funding: Funding has been provided by the American Board of Family Medicine, which contracts annually for health policy/health services research conducted by the Robert Graham Center for Policy Studies-related Maintenance of Certification and Quality.

Conflict of interest: none declared.

Corresponding author: Stephen Petterson, PhD, 1350 Connecticut Ave, \#201, Washington, DC 20036 (E-mail: spetterson@aafp.org).

\section{See Related Article on Page 633.}

The results affirm the broad scope of practice inherent to family medicine and its variation across the rural to urban continuum. With increasing rurality, primary care physicians increasingly provide care in hospital, emergency room, and surgical settings. Defining primary care based on provision of a select set of $\mathrm{E} \& \mathrm{M}$ codes, however, disproportionately excludes many rural physicians who are more likely to provide non-E\&M services. Using the Patient Protection Affordable Care Act approach, we found that just $53 \%$ of family physicians and $33 \%$ of other primary care providers would be eligible for the Medicare bonus.

In light of our findings, the Centers for Medicare and Medicaid Services has revised its approach to calculating the threshold. Their remedy-excluding hospital services when determining total charges-increases the eligibility of family physicians to $80 \% .{ }^{1}$ Although this is a step in the right

Figure 1. Percent of family physician claims by type of service and rurality.

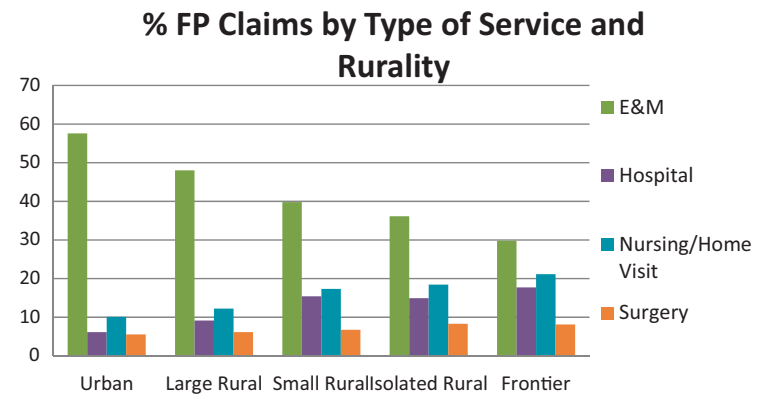


direction, some family physicians, especially those in rural areas, still risk being penalized rather than rewarded for a broad scope of practice. The versatility of family physicians in adapting to meet their communities' primary care needs, especially those in rural areas, may defy any single category of E\&M or Current Procedural Terminology codes. In addition, policymakers must adapt any definition used to increase primary care payment to serve a broader goal: to support primary care practices, not just physicians.

\section{References}

1. http://edocket.access.gpo.gov/2010/pdf/201027969.pdf. 